\title{
The relationship between child, adolescent and adult psychiatry
}

\author{
Michael Fitzgerald
}

Ir J Psych Med 1997; 14(2): 42

There is an association between child and adult (parental) psychiatric problems, as there is between childhood and parental mental health problems and longitudinally between childhood problems and adult problems. The following is some of the evidence.

McNestry ${ }^{1}$ et al showed that $44 \%$ of mothers of children attending a child and family centre were depressed. Leader ${ }^{2}$ et al found high rates of depression in mothers of children attending a preschool group. In a study of mothers who were patients in an adult psychiatric hospital it was found that $72 \%$ of their children showed evidence of having significant problems in social competence. ${ }^{3}$ In addition there is considerable continuity between child problems and adult problems. ${ }^{4}$ A follow up study of children and adolescents with depressive disorder found that five years later $50 \%$ were showing evidence of depression and maternal depression was the best predictor of child and adolescent depression at follow up. ${ }^{4}$ The majority of factors that were associated with maternal depression were also associated with child psychiatric disorder eg. social isolation, marital disharmony, low income ${ }^{5}$ etc. In a community study there was relatively low rates of identification and referral of children with psychiatric problems for treatment. ${ }^{6}$ Over the past 20 years I can only remember very rare referrals of children from adult psychiatrists. It often makes no sense for adult psychiatrists to assess their patients who have children simply in isolation from other family members particularly the children. Equally it makes little sense for child psychiatrists to assess children referred to them in isolation from parental psychiatric problems and indeed child psychiatrists do pay far greater attention to parental problems than adult psychiatrists do to the children of their adult patients.

Patients don't come neatly compartmentalised for adult psychiatric specialists or child psychiatric specialists. In reality there is a great deal of overlap between the psychiatric problems of parents and children. It therefore makes sense that a holistic approach is taken. Adult psychiatrists have the capacity and are in a unique position to practice preventive child psychiatry. There is evidence that children

Michael Fitzgerald, MD, MRCPsych.

Henry Marsh Professor in Child \& Adolescent Psychiatry, Trinity College Dublin.

Consultant Child Psychiatrist, Child and Family Centre,

Ballyfermot Road,

Dublin 10, Ireland.

SUBMITTED: APRIL 1997. of parental adult patients with depression who are given proper psychoeducational interventions are less likely to become depressed themselves. ${ }^{7}$ Equally child and adolescent psychiatrists have to be able to conduct parental psychotherapy and to deal with parental anxieties and depressive symptoms. Clearly parents with schizophrenia, manic depressive psychosis and organic brain syndromes will need referral to adult psychiatrists. It is interesting that in continental Europe there is a qualification in child psychiatry and psychotherapy. This is an excellent combination and one that should also be considered in the United Kingdom and Ireland.

While subspecialisation has advantages it also has serious disadvantages which have not been properly considered by training organisations at post graduate level. The extreme slowness in getting a proper continuous psychiatric development programme into existence is also a further detrimental factor.

It is necessary for psychiatric teams to consider providing "total psychiatric care" for all members of families referred to them who have particularly more minor psychiatric problems. Families cant cope with the stress caused by endless fragmentation of subspecialisation. Psychiatric teams have to become more "user friendly" and deal with the family in a holistic fashion. Unfortunately for psychiatry with the increased emphasis on biology, neuroimaging etc. it is likely that the patient will be seen more and more in the classic medical isolated sense and John Donne's statement made in 1624 "no man is an island, entire of itself" will be forgotten. This will increase the alienation so many patients today already feel.

\section{References}

1. McNestry FB, Fitzgerald M, Kinsella A. Maternal mental health, childhood behaviour problems and social disadvantage in families of children attending a child guidance clinic. Ir J Psychiatry 1988; 9: 14-7. 2. Leader H, Fitzgerald M, Kinsella A. Behaviourally deviant preschool children and depressed mothers. Ir J Med Sci 1985; 154(3): 106-9.

3. O'Leary Z, Fitzgerald M, Naidu $M$. The study of behavioural deviance and social competence in children of psychiatric inpatient females. Ir J Psychiatry, 1989; 10(2): 8-10.

4. Robins LM. Deviant children grown up. Baltimore; Williams and Wilkins, 1966.

5. Fitzgerald M, Jeffers A, Kinsella A. A follow up of depressive illness in childhood. Br J Clinical and Social Psychiatry, 1994; 9(1): 12-15.

6. Fitzgerald $M$, Jeffers $A$. Psychosocial factors associated with psychological problems in Irish children and their mothers. Economic and Social Review 1994; 125(4): 285-301.

7. Beardslee W, Wright E, Salt P, Drezner BA, Gladstone T, Versage E, Rothberg P. Examination of children's responses to two preventive intervention strategies over time. J Am Acad Child Adolesc Psychiatry, 1987; 36(2): 196-204. 